\title{
Abrupt seasonal transitions in land carbon uptake in 2015 Supplementary Material
}

Chao Yue ${ }^{1}$, Philippe Ciais ${ }^{1}$, Ana Bastos ${ }^{1}$, Frederic Chevallier $^{1}$, Yi Yin ${ }^{1}$, Christian Rödenbeck ${ }^{2}$

${ }^{1}$ Laboratoire des Sciences du Climat et de l'Environnement, CEA-CNRS-UVSQ, UMR8212, Gif-surYvette, France

${ }^{2}$ Max Planck Institute for Biogeochemistry, Jena, Germany.

Corresponding author: chao.yue@1sce.ipsl.fr

Figure 1 Rank of mean seasonal NDVI for the four seasons 2015 (Q1 = January to March, Q2 = April to June, Q3 = July to September and Q4 = October to December) over the period 2000-2015. Larger numbers correspond to higher NDVI, with 16 (magenta colour) indicating grid cells where NDIV reached the highest in 2015.
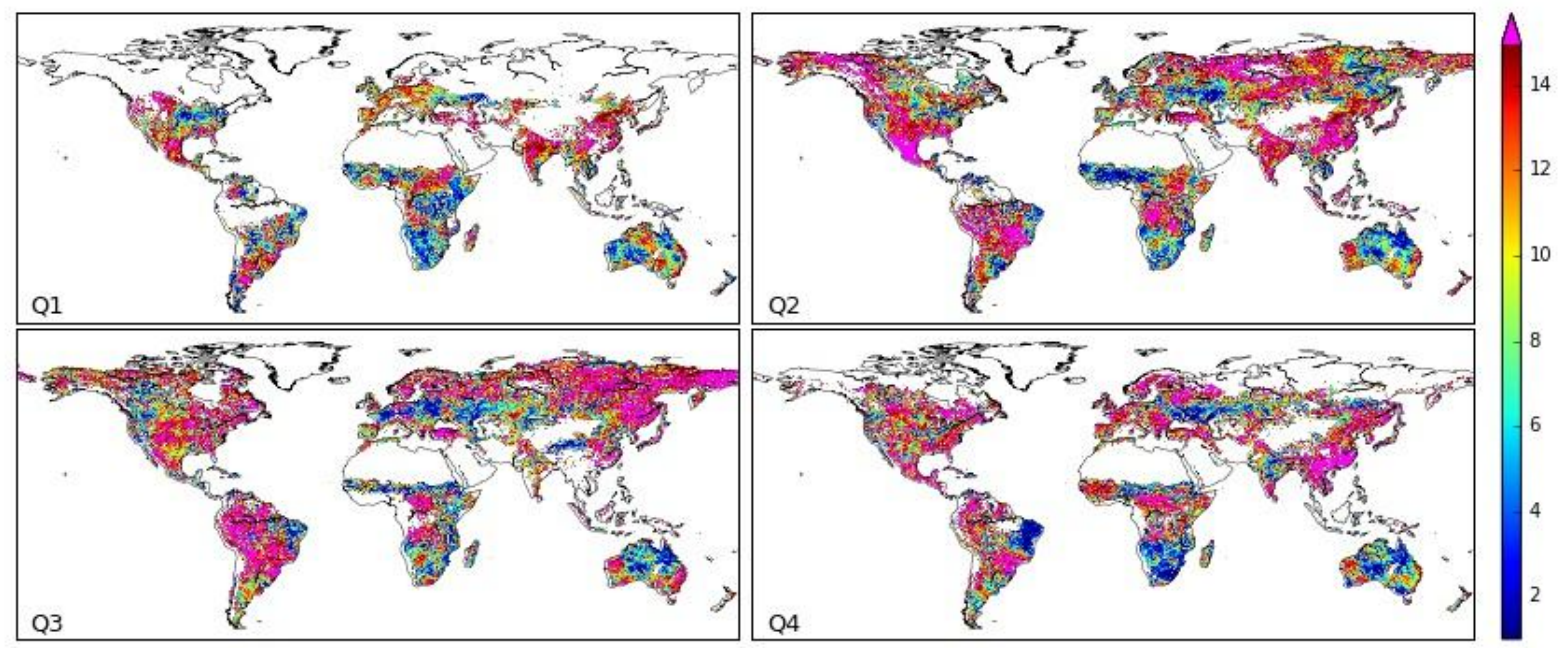

Figure 2 Detrended seasonal anomalies of land carbon uptake for the four seasons of the year $2015(\mathrm{kgC}$ $\mathrm{m}^{-2}$ season $^{-1}$ ), the two inversion systems, (a) CAMS and (b) Jena04.

a) CAMS: 

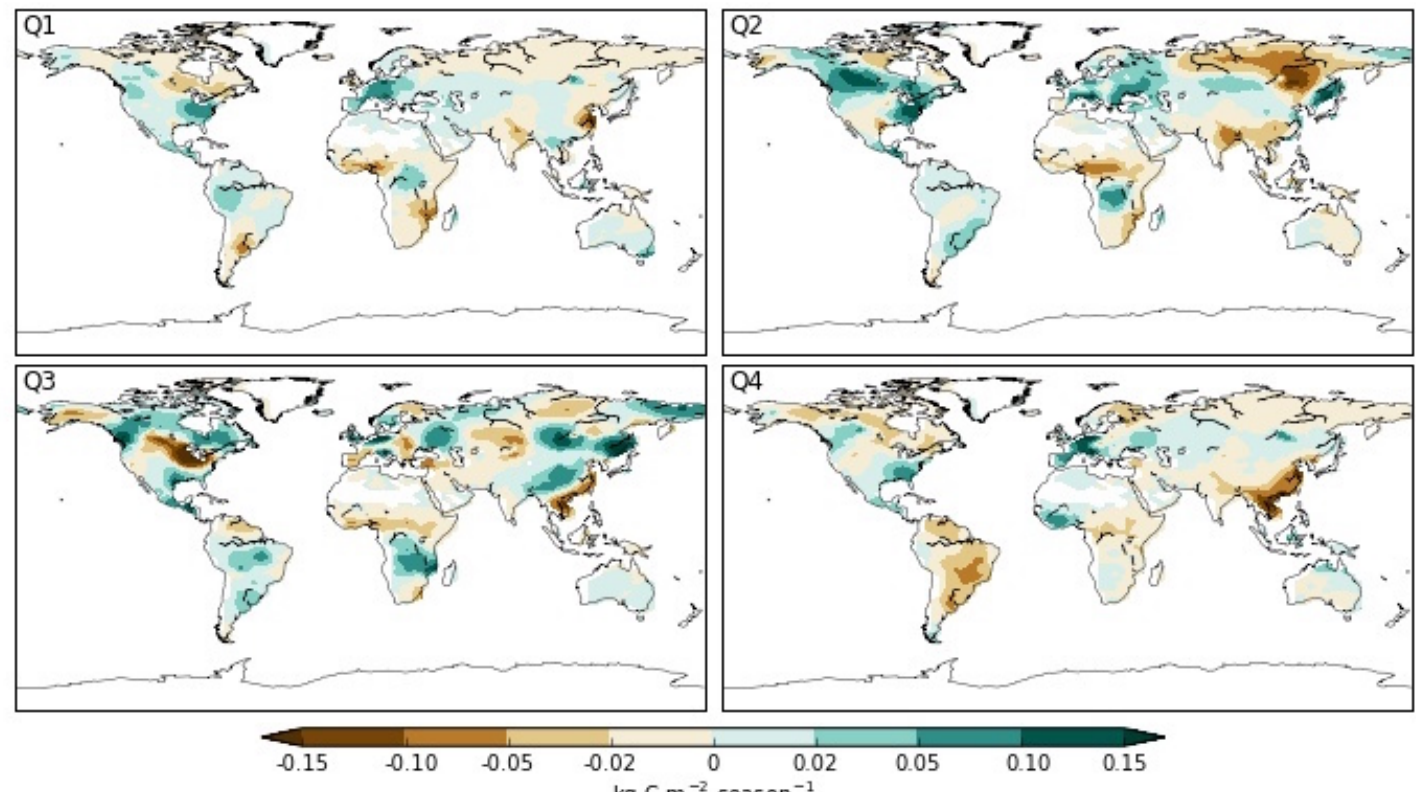

$\mathrm{kg} \mathrm{C} \mathrm{m}^{-2}$ season $^{-1}$

b) Jena04:
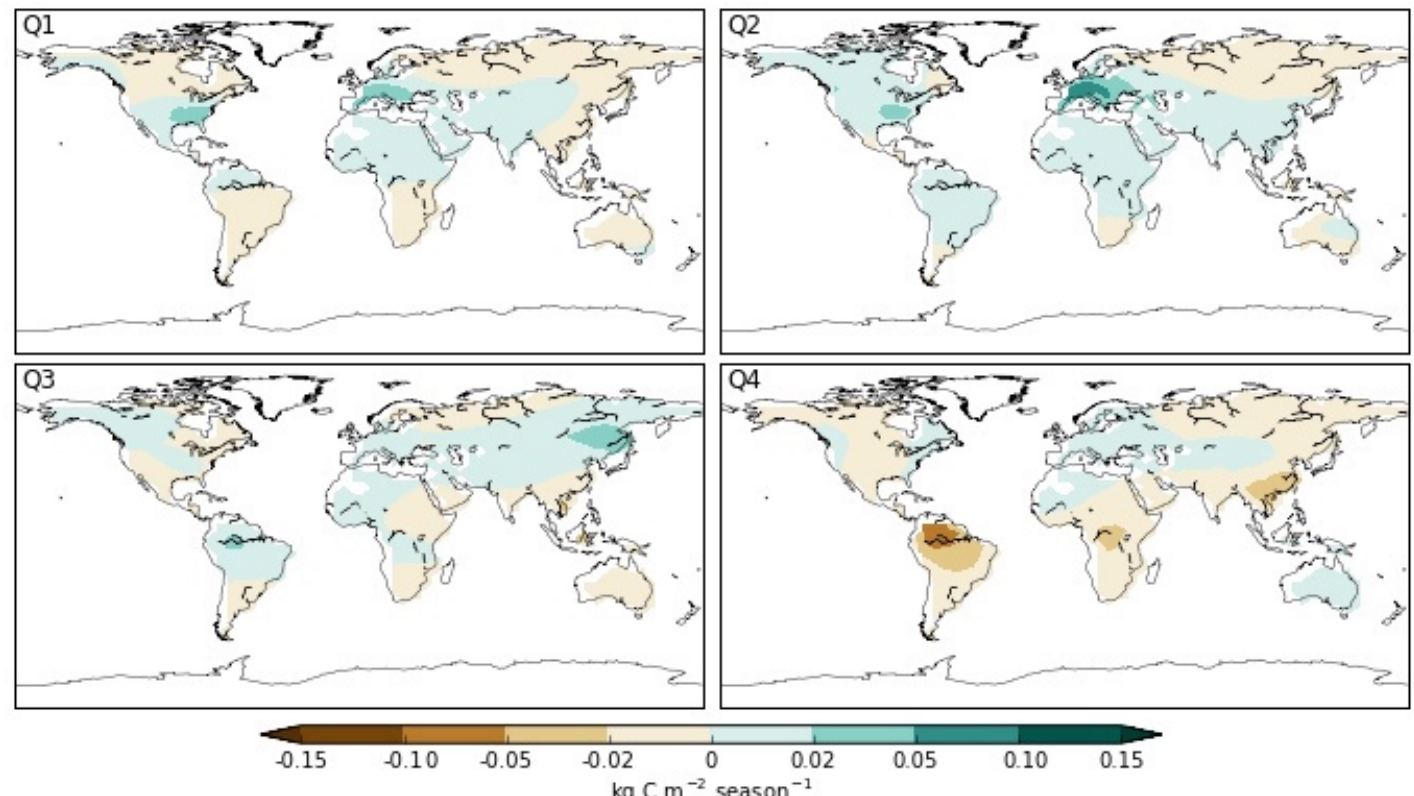

Figure 3 Anomalies of land carbon uptake linearly detrended for 1981-2015 for different seasons in 2015, estimated by the CAMS (blue) and Jena04 (orange) inversion data. Data are shown for: (a) boreal Northern Hemisphere $\left(\mathrm{BoNH}\right.$, latitude $\left.>45^{\circ} \mathrm{N}\right)$, (b) temperate Northern Hemisphere $\left(\mathrm{TeNH}, 23.5^{\circ}<\right.$ latitude $<45^{\circ} \mathrm{N}$ ) the two sub-regions of (c) BoTeNH defined in the main text. Dots indicate seasonal values with solid dots indicating that the anomaly is below the 10th or above 90th percentile over 19812015. Vertical bars indicate the annual sum. 


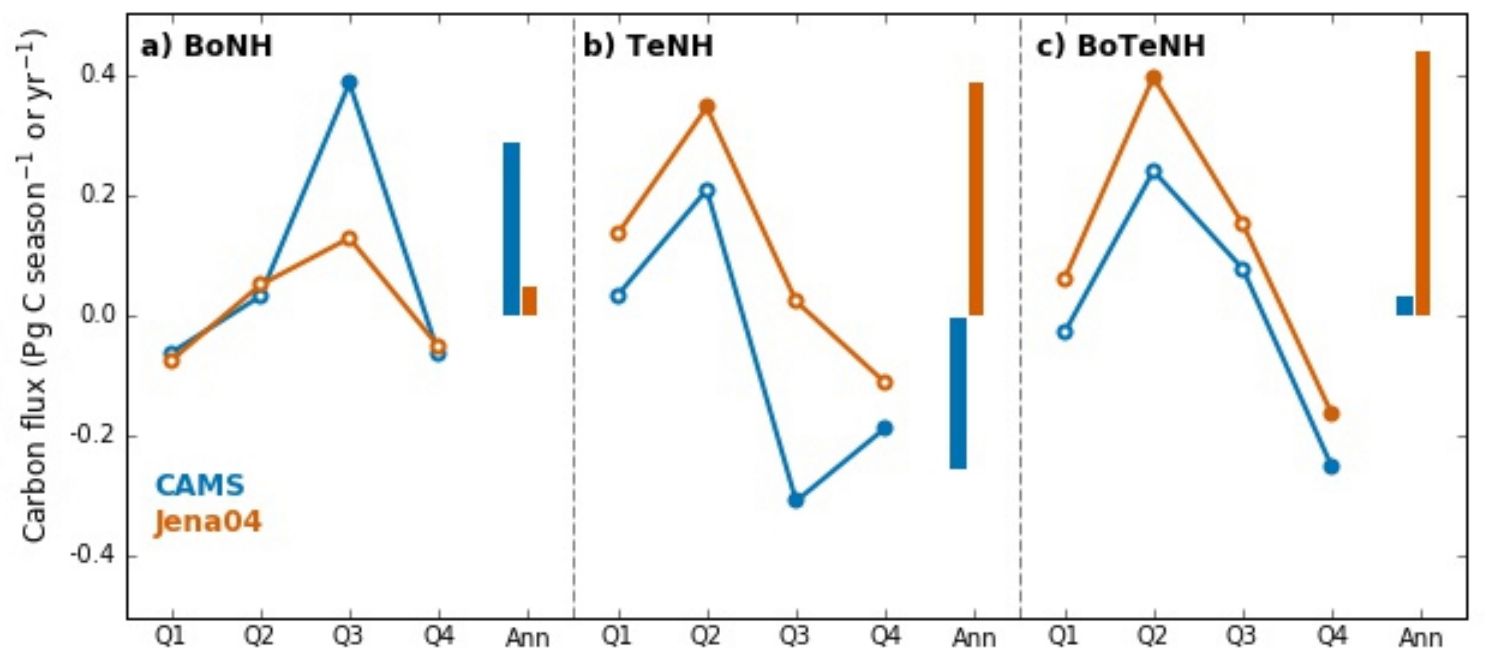

Figure 4 Detrended seasonal climate anomalies for 2015: (a) air temperature and (b) volumetric soil water content from ERA interim reanalysis. Hatched regions indicate $<10$ th or $>90$ th percentile over 1981-2015.

\section{(a) air temperature}

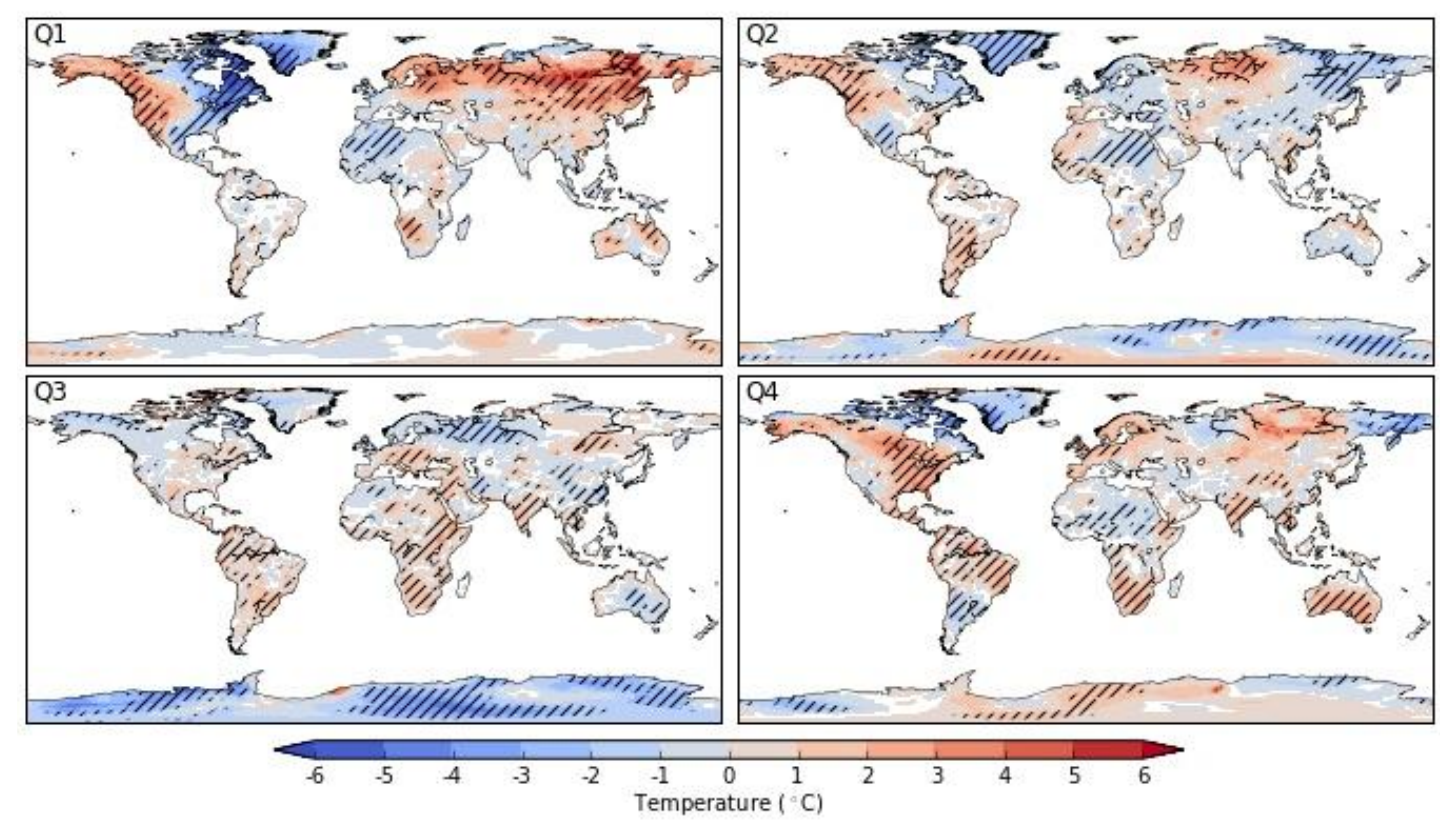

(b) soil water content 


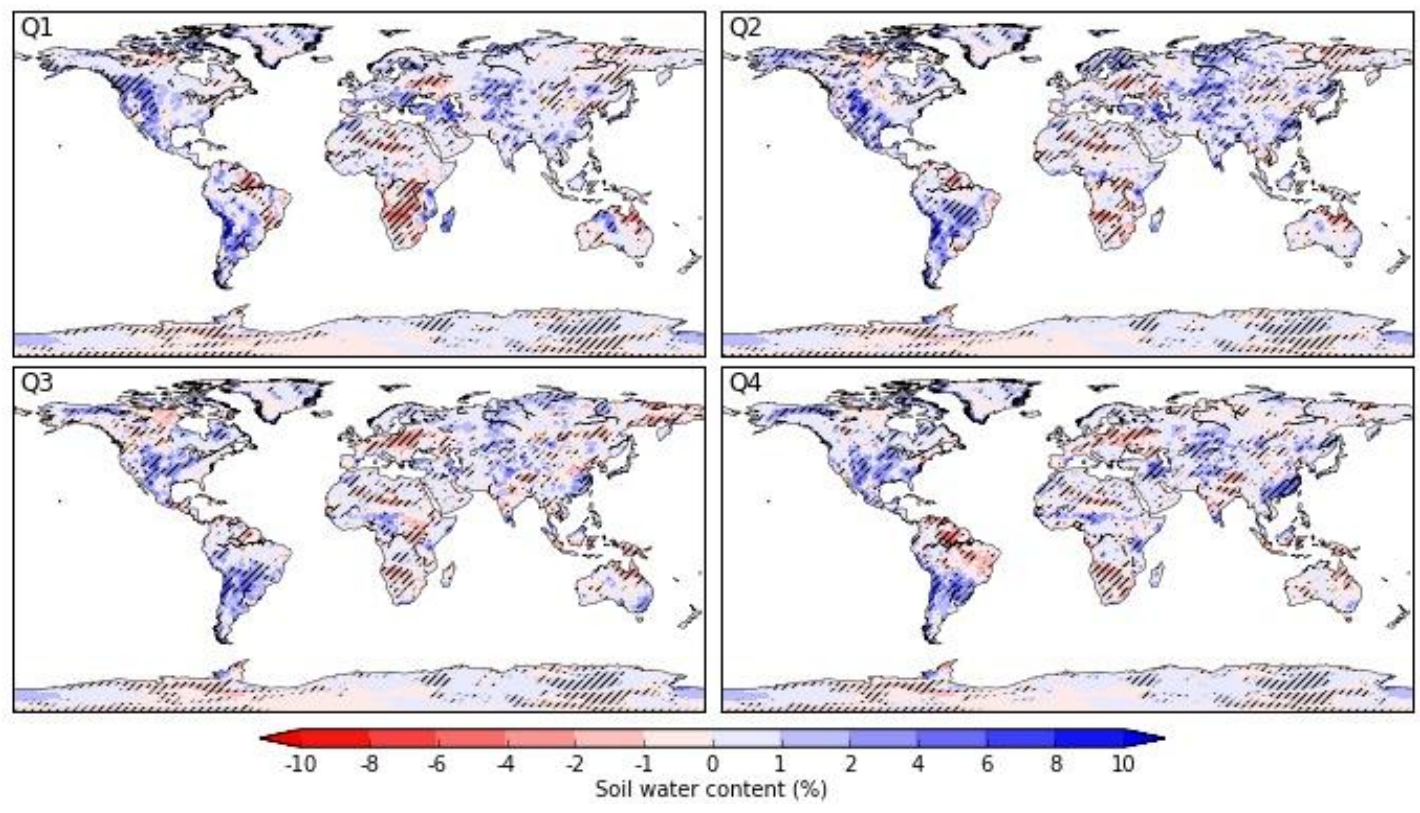

Figure 5 The evolution of El Niño events during 2014-15 and comparison with that of 1997-98, and its influence on climate and carbon uptake variations over land in the tropics and extratropical Southern Hemisphere ( $\mathrm{TroSH}$, latitude $<23.5^{\circ} \mathrm{N}$ ). The state of ENSO in warm (El Niño) or cold (La Niña) phase is indicated by the Multivariate ENSO Index (MEI). Positive values of MEI indicate a warm phase, and negative a cold phase. All other variables are shown as monthly anomalies with linear trends being removed for each month over 1981-2015 except for fire carbon emissions for which the detrending time window is 1997-2009. Fire emissions are derived from GFED4s data. For fire emissions, TroSH is further divided into three sub-regions: northern tropics $\left(0^{\circ}<\right.$ latitude $\left.<23.5^{\circ} \mathrm{N}\right)$, southern tropics $\left(0^{\circ}<\right.$ latitude $<23.5^{\circ} \mathrm{S}$ ) and southern extra-tropics (latitude $>23.5^{\circ} \mathrm{S}$ ). Antarctica is excluded when making the analysis. Data are shown for 1997-98 and 2014-16. The shaded area indicates Q4 (October to December) of 2015. Note the different $\mathrm{Y}$-axis scales for subplots of fire emissions. 


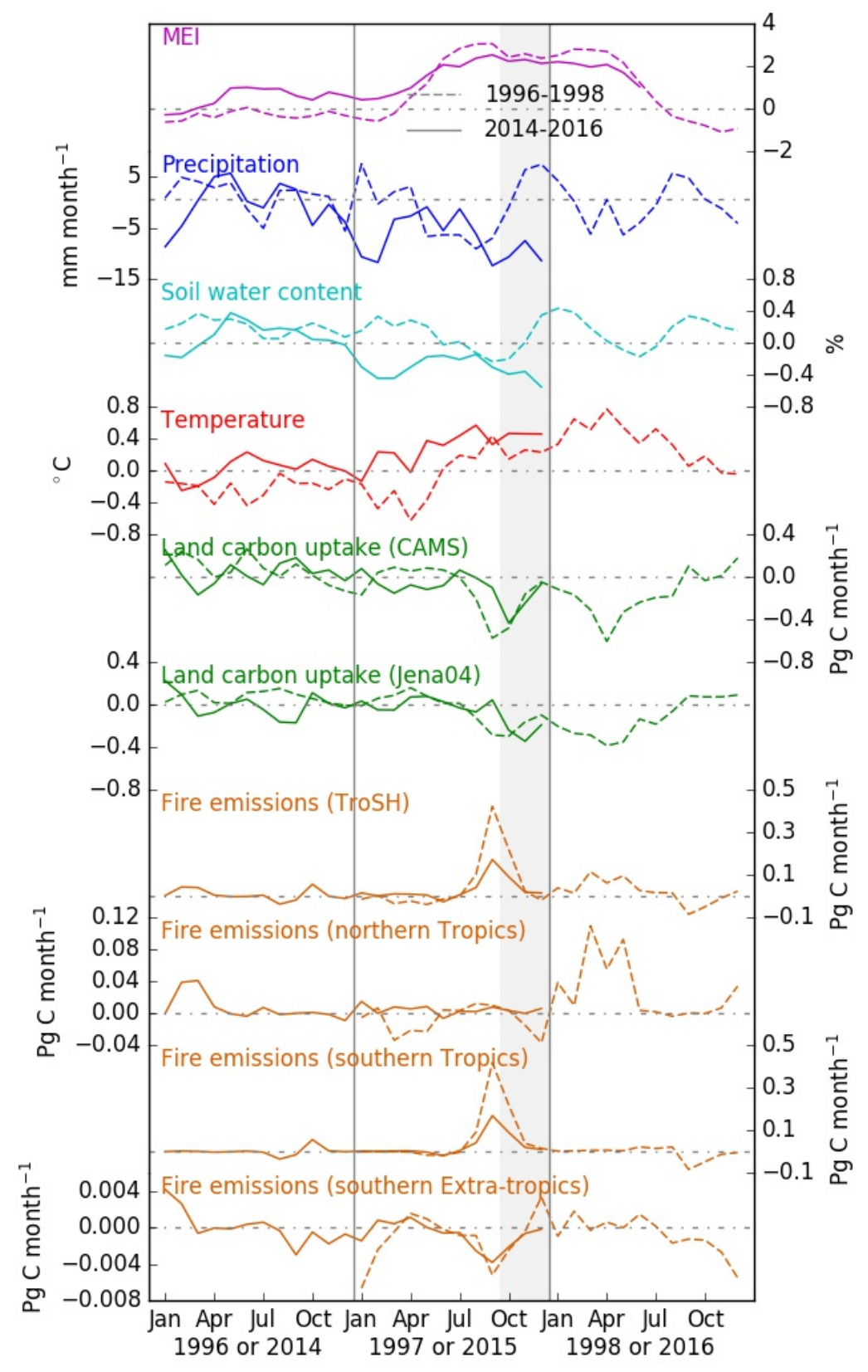

Figure 6 Measurement sites for 2015 used in (a) CAMS and (b) Jena04 inversions. (a) CAMS 


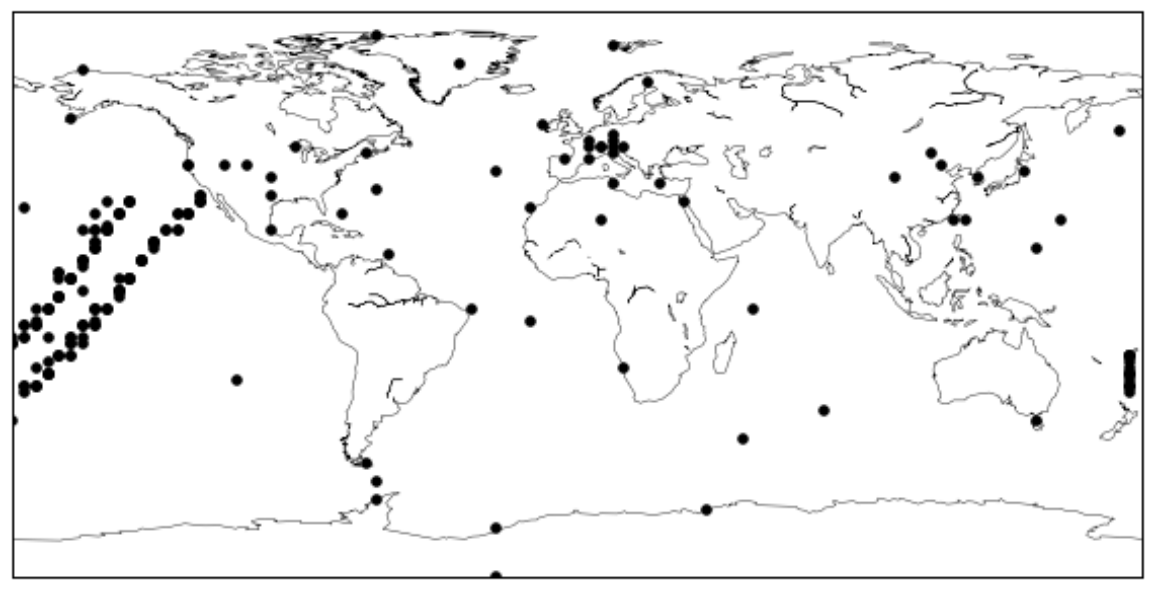

(b) Jena04

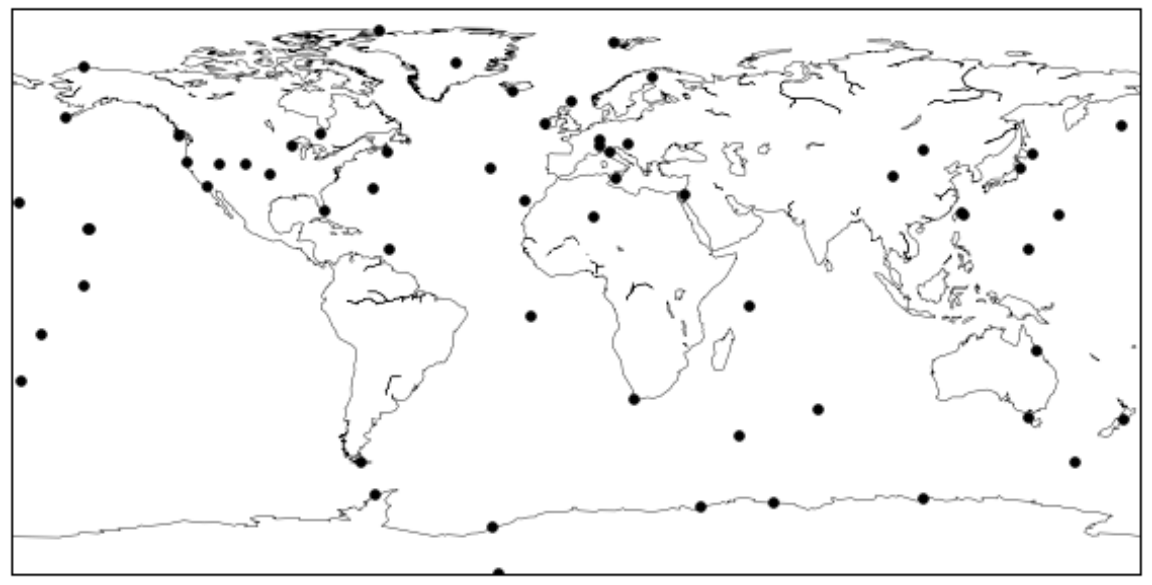

